\title{
Factors Affecting Consumers' Willingness to Join (WTJ) and Willingness to Pay (WTP) for Rain Water Harvesting System (RWHS) for Household Needs: A Case Study in the Northern Part of Sri Lanka
}

\author{
V. Jeyakrishnan* and K. Umashankar \\ Faculty of Graduate Studies \\ University of Jaffna \\ Sri Lanka
}

\begin{abstract}
An escalation in the population, pollution and contamination of fresh water bodies in the island nation exerts a strain on adequate supply of fresh water. When it comes to fresh water supply the condition in the dry zone is far more acute than in the rest of the island. This feature is intensively felt in the Jaffna peninsula. In consideration of this situation, the researchers deliberated on applying traditional concepts with modern alterations to conserve and store rain water at household levels. Thus, the researchers had taken effort to (i) ascertain consumer willingness to join, (ii) ascertain consumer willingness to pay for the bid and (iii) identify the socio economic factors influencing the choice of individuals. The city of Jaffna within municipal limits was selected for this purpose and around 300 respondents were picked randomly corresponding to the population of the relevant secretarial divisions. The collected data were analyzed within the frame work of contingent valuation (CV) method, using Probit and Multinomial Logit Regression. The results revealed that household WTJ depends on education, household size, income, media exposure index and real estate extent. These factors again influenced positively and were statistically significant. Similarly household WTP is positively influenced by education, age, household size, media exposure index, real estate extent and income which were statically significant. Thus, increasing media exposure relevant to the immediate need, extending a knowledge of the ground reality in a wide range, making available credit facility essentially for the institution of RWHS for the economically unstable, will make the supply of RWHS for all possible, thus making the storage and use of fresh water a success in the peninsula region.
\end{abstract}

Keywords: Contingent valuation method, Probit regression, Multinomial Logit, rain water harvesting system, willingness to join and pay, Jaffna.

\section{INTRODUCTION}

Water plays an important role in all the life forms on the planet. Existence of life depends on water. Health in general depends on the availability of adequate, accessible, reliable and safe, drinking water supplies. Clean water is crucial for human health. Hence, great attention has to be paid in acquiring quality water for consumption. Demand for clean water increases proportionately with increasing population. Global demand for freshwater is increasing by 64

\footnotetext{
* Corresponding author: nvruby2009@yahoo.com
} 
billion cubic meters a year (AQASTA, 2015). More than 750 million people around the world, approximately one in nine people lack access to safe water (WHO and UNICEF, 2014) and diarrhoea caused by poor sanitation and subsequent drinking water scarcity inadequate drinking water kill approximately 2300 people a day (Annette Prüss-Ustünet al.,2014). Continuous increasing population in conjunction with the climate change, contamination and pollution of fresh water sources exerts a strain on the availability of quality fresh water for consumption. Hence, availability of fresh water for a modest payment is becoming a critical item in the global agenda. The Virginia-U.S rain water harvesting manual compiled by the Cabell brand center in 2007 stated that rain water can offer a sustainable alternative for potable water resource. Rain water harvesting has been again identified as a viable alternative at the climate change convention held in Nairobi-Kenya2006 in addressing fresh water needs. Rain water harvesting is the capture of rain where it falls or at the runoff from higher elevation and storing the water for future use. Rain water harvesting technology has been practiced from earliest times providing potable water for domestic, agricultural and industrial use. Sri Lanka is no exception to the problem of water inadequacy, being a third world country and an island in the Indian Ocean. In Sri Lanka rain water harvesting has a history of about 2500 years being traced back to earliest civilizations. The island receives fair amounts of rain from the monsoonal and inter monsoonal rain falls. Hence, it is rather important that the need for rain water harvesting facilities be properly recognized. There has been declaration of a national policy on rain water harvesting in 2005. The ministers of five SAARC countries signed a memorandum of understanding in the city of Kandy, further stressing the importance of rain water harvesting. The legislation for the promotion of rain water harvesting was published by the urban development authority under act No: 36 of 2007.

The situation of fresh water supply in the dry zone is far more acute than in the rest of the island. This feature is intensively felt in the Jaffna peninsular. The population in Jaffna peninsula is dependent for its fresh drinking water supply for totally on the ground water. This supply however is dependent on the monsoonal rain for replenishment. Even though most parts of the island is able to supply fresh water for drinking from surface sources such as ponds, lakes, mountain rivers and springs, this provision is absolutely not available in the peninsular region. The Jaffna peninsular forms the Northern end of Sri Lanka. The soil feature is limestone rock, which is unique to the peninsular region alone as against the rest of the island. The Jaffna district by extent is $1023 \mathrm{Sq} \mathrm{Km}$ that includes inland water bodies. The district is essentially agricultural, being ideally suited for cultivation of commercial crops. The Jaffna peninsula as a whole lies beneath Miocene limestone formations which are generally $100-150 \mathrm{~cm}$ thick and are distinctly bedded, well jointed and highly karstified. The shallow aquifer of the peninsula occurs in the channels and cavities (Karsts). All the shallow ground water found within the Karstic cavities were created by the infiltration of rainfall. This shallow groundwater forms mounds or lenses which float over the saline water and reach their peak during the monsoon rains of November to December (Balendran et al., 1968, Rajasooriar et al., 2002). Ground water serves as an essential and safe source of water for the peninsular residents, water resources of the basin remain almost constant, but the need for water keeps increasing.

The existing water source is the water in the aquifer. The per capita requirement of fresh water is the future dangerously precarious due to salinity. Contribution to salinity is made by constant and indiscriminate dewatering of the wells in the region. Sea water seepage into the aquifers, results in the fresh water lens becoming saline (Balendran et al, 1968, Nandakumar, 1983). This condition has been aggravated by increasing population, dewatering using pumps for agricultural and domestic purposes and pollution and contamination. Concentrated 
agriculture with extensive use of agrochemicals affects underground water purity. Leaching nitrate into water makes water unsatisfactory for human consumption. Faulty designs of soakage pits lead to pollution of ground water. Researches have revealed that in Point-pedro nitrate concentrations ranged from $122-174 \mathrm{mg} / \mathrm{l}$ due to sewage pollution. The most common and widespread health hazard associated with drinking water is the bacterial contamination caused either directly or indirectly by human waste and animal waste. The percentage bacteriological content of groundwater is one of the most important concerns in ensuring drinking water quality. The presence of Escherichia coli is an indicator of bacteriological contamination. Improper waste disposal is one factor rendering water impure, for drinking purposes. Water contamination on a large scale is manifested in the peninsular region due to agrochemical washout and septic tank soak ways. Traces of toxic heavy metals including $\mathrm{Cd}$, $\mathrm{Pb}$ and as were observed in the Chunnakam aquifer system. Due to oil leakage and excessive use of agrochemicals, those heavy metal contents exceeded WHO limits for drinking water. The foregoing details indicate that the peninsula is confronted with having to supply an increasing population with fresh water, while such water bodies with with fresh water continue to get contaminated. Therefore, alternative sources for fresh water need to be explored, to provide everybody in Sri Lanka with safe drinking water.

To address the prevailing urgency, rain water harvesting is considered the best sustainable and economically viable solution. In providing rain water harvesting systems at domestic levels, it is possible to store fresh water supplies without allowing the water to reach surface soil. The collection of water at an elevation, needs a system which is durable and design to maintain the quality of rain water for a period of time. Conservation and storage of rain water has been practiced in Sri Lanka for a long time, which is evident from the tanks, channels and canals. In the developed world rain water harvesting is adopted with a high degree of technical expertise very successfully, thus complementing their fresh water supply with surplus water. Research reveals that rain water harvesting systems could be successfully instituted in the Jaffna peninsula. At present, the Iranaimadu reservoir satisfies the water requirement of the peninsular. Dspite the reservoir, the Vanni region routinely suffers from devastating drought which results in drying out of thousands of acres of paddy lands. Severe drought may affect the reservoir water level while heavy rains may wash grochemicals and other pollutants into reservoir water increasing health hazards amount. It is well known that the Iranamadu reservoir is not able to satisfy the total water requirement of the Jaffna peninsula.

In comparison to the construction costs for the delivery of water to the penninsular from the Iranaimadu reservoir, it seems advantageous to employ rain water harvesting systems throughout the peninsula.

Considering all these socio economic factors and the viability of a variety of solutions, this study was conducted to determine (i) Consumer willingness to join (ii) consumer willingness to pay for the bid and (iii) the socio economic factors influencing choice of an individual.

\section{METHODOLOGY}

The city of Jaffna was selected as the study site for this purpose. A stratified random sampling technique was employed in selecting the household. Jaffna and Nallur divisional secretariat are the two divisions in the Jaffna town, from where the population data were collected. Around 300 respondents were selected randomly, corresponding to the population density of the relevant divisional secretariat divisions. Samples were proportionately 
distributed among each divisional secretariat of Jaffna municipal council. The data collection was carried out by using an interview administered structured questionnaire and amended accordingly. This questionnaire was subjected to pre testing by interviewing five respondents. The data were collected on current water needs, health concerns and household socio economic characteristics. Questionnaire consisted of a mixture of open ended, open ended with pre-qualifying statements, and accenting bid dichotomous choice questions. The direct interviews were arranged with the households at their residences. During the interview direct observation on environment of the household was also made and recorded.

In this study, researchers created a hypothetical market for the respondents to expose their maximum WTP for the demand of rainwater harvesting. Generally, hypothetical markets are proposed to place the respondents in an actual world market like situation to be able to purchase the targeted products by expressing their preference for the good in question. In this concern, the purpose of the hypothetical market was to set up a market for the rainwater harvesting. A picture of the scenario was also shown to the respondents with pollution incident and reduction of water quality. They were exposed to a visual demonstration of the hypothetical market that has been described verbally. These verbal explanation and presentation were used to explain the techniques that could be made available in real terms to the community.

\section{Model specification for willingness to join}

The estimating model that emerges from the normal cumulative density function (CDF) is popularly known as the Probit model. Probit models are the better-known discrete choice models. These models are based on utility theory or rational choice perspective on behavior, as developed by McFadden. Probit model is an extension and improvement of the linear probability model (Gujarati, 2003), which in the context of WTJ takes the following regression form:

$$
Y_{i}=\beta_{1}+\beta_{2} X_{i}+\varepsilon_{i}
$$

Where, Xi represents the explanatory variables related to the $\mathrm{i}^{\text {th }}$ consumer socio economic characteristics. The dependent variable, Yi, is equal to 1 if the consumer is willing to join for RWHS and 0 otherwise. The $\beta_{1}$ is the intercept. The value of the parameter, $\beta_{2}$, measures the marginal impact of a unit change in the consumer's socio-economic characters on the probability of WTJ for RWHS. $\varepsilon_{i}$ is the random error term. To avoid the serious weakness of having predicted values, Yi falling outside the $(0,1)$ range, they are to be interpreted as probabilities. But we don't actually observe the probabilities, but only observe the outcomes $(\mathrm{Yi}=1$ or $\mathrm{Yi}=0)$. Each $\mathrm{Yi}$ is a Bernoulli random variable. Hence the probability can be written as,

$$
\begin{aligned}
\text { WTJ is } \operatorname{Pr}(Y i=1) & =P i \\
\text { not WTJ is } \operatorname{Pr}(Y i=0) & =(1-\mathrm{Pi})
\end{aligned}
$$

Now $\mathrm{Pi}$ / (1-Pi) is simply the odds ratio in favor of willingness to join with RWHS the ratio of the probability that a farmer willingness to join to the probability that farmer will not willingness to join. Now if the natural log for probability ratio is taken,

$$
L_{i}=\ln \left(\frac{P_{i}}{1-P_{i}}\right)=\beta_{1}+\beta_{2} X_{i}+\varepsilon_{i}
$$


That is, $\mathrm{L}_{\mathrm{i}}$, the $\log$ of the odds ratio, is not only linear in $\mathrm{X}$, but also linear in the parameters.

\section{Model specification for willingness to pay}

Environmental methodology describes six phases in the practical application of the CVM. These are the market description, elicitation, calculation, estimation, aggregation and validation phases (Quartry, 2011, Batement and Turner, 1995). For the purpose of finding out WTP for RWHS multinomial logistic model is used according to Lemeshow and Sturdivant (2013), Green (2012), Treiman (2009), Long and Frees (2006), Long (1997).In the research the dependent variable outcomes are $1,2,3 \ldots \mathrm{m}$ denoting categories as small , medium, large and extra-large RWHs which is recorded in Y, and the explanatory variables in $X$. Even though the outcomes are coded $1,2,3 \ldots$, the numerical value are arbitrary because $1<2<3$. This categorical property of $\mathrm{Y}$ distinguishes the use of outcomes, which can be thought of as ordered. In the multinomial logit model, there is a set of estimated coefficients as $\beta^{(1)}, \beta^{(2)}, \beta^{(3)}$ corresponding to each out comes.

$$
\begin{gathered}
\operatorname{Pr}(y=1)=\frac{e^{X \beta(1)}}{e^{X \beta(1)}+e^{X \beta(2)}+e^{X \beta(3)}} \\
\operatorname{Pr}(y=2)=\frac{e^{X \beta(2)}}{e^{X \beta(1)}+e^{X \beta(2)}+e^{X \beta(3)}} \operatorname{Pr}(y=3)=\frac{e^{X \beta(3)}}{e^{X \beta(1)}+e^{X \beta(2)}+e^{X \beta(3)}}
\end{gathered}
$$

In this model, there is a situation as unidentified in the sense that there is more than one solution to $\beta^{(1)}, \beta^{(2)}$ and $\beta^{(3)}$ that leads to the same probabilities for $y=1, y=2$, and $y=3$. For the purpose of identify the model, arbitrarily set one of $\beta^{(1)}, \beta^{(2)}$ or $\beta^{(3)}$ to 0 . There is, if arbitrarily set $\beta^{(1)}=0$, the remaining coefficients $\beta^{(2)}$ and $\beta^{(3)}$ will measure the change relative to the $y=1$. If the instead set of $\beta^{(2)}=0$, the remaining coefficient $\beta^{(1)}$ and $\beta^{(3)}$ will measure the change relative to $y=2$. The coefficients will differ because they have different interpretations but the predicted probabilities for $y=1,2$ and 3 will still be the same. Setting $\beta^{(1)}=0$, the equation become

$$
\begin{aligned}
& \operatorname{Pr}(y=1)=\frac{1}{1+e^{X \beta(2)}+e^{X \beta(3)}} \\
& \operatorname{Pr}(y=2)=\frac{e^{X \beta(2)}}{1+e^{X \beta(2)}+e^{X \beta(3)}} \\
& \operatorname{Pr}(y=3)=\frac{e^{X \beta(3)}}{1+e^{X \beta(2)}+e^{X \beta(3)}}
\end{aligned}
$$

The relative probability of $\mathrm{y}=2$ to the base outcome is

$$
\frac{\operatorname{Pr}(y=2)}{\operatorname{Pr}(y=1)}=e^{x \beta(2)}
$$

Where consider the relative risk ratio, further assume that $\mathrm{x}$ and $\beta_{\mathrm{k}}{ }^{(2)}$ are vectors equal to $\left(\mathrm{x}_{1}\right.$, $\mathrm{x}_{2}, \mathrm{x}_{\mathrm{k}}$ ) and $\left(\beta_{1}{ }^{(2)}, \beta_{2}{ }^{(2)}, \ldots \ldots, \beta_{\mathrm{k}}{ }^{(2)}\right)$, respectively. The ratio of the relative risk for a one unit change in $x_{i}$ is then 


$$
\frac{e^{\beta_{i}^{(2)} x_{i}+\ldots \ldots .+\beta_{i}^{(2)}\left(x_{i}+1\right)+\ldots \ldots . .+\beta_{k}^{(2)} x_{k}}}{e^{\beta_{i}^{(2)} x_{i}+\ldots \ldots .+\beta_{i}^{(2)} x_{i}+\ldots \ldots .+\beta_{k}^{(2)} x_{k}}}=e_{i}^{\beta(2)}
$$

Thus the exponentiated value of a coefficient is the relative risk ratio for one unit change in the corresponding variable (risk is measured as the risk of the outcome relative to the base outcome)

\section{RESULTS AND DISCUSSION}

\section{Discussion on regression diagnostic tests}

Heteroscedasticity emerges as an obviously serious problem in Tobit (Green, 2012). The outliers were observed with the collected data particularly with the household income and household size. This will create heteroscedasticity problem. Hence the extreme outliers were removed from the sample. But unfortunately removing all outliers would tend to reduce the overall sample size. Consequently the authors decided to eliminate only the extreme outliers totally. Anyhow authors assumed the presents of heterocedasticity problem with the data and estimated the white heterocedasticity - correlated standard errors (known as robust standard error) and performed the correction. Forrar and Glaubar have suggested that one should look at the partial correlation coefficients (Gujarati 2003). It is reasonable to expect a relationship among the explanatory variables. The presents of multicollinearity under the limited dependent variable, based on the decision rule if partial correlation coefficient between two variable exceeds the value of 0.6 , then, it indicate the presents of multicollinearity problem. But based on the correlation matrix it was observed that none of the partial correlation coefficient was not exceeded 0.6. Hence there is no reason to suspect multicollinearity between the explanatory variables. Researchers also adopted the Klien's rule too by performing auxiliary regression and compared the results with overall OLS regression.

\section{Discussion based on the descriptive statistics}

The sample shows that out of 300 households, $63.3 \%$ are using dug wells as the source for drinking water, while $23.3 \%$ of households are using tube wells as water sources, $13.3 \%$ are using pipe borne water, the remaining $0.7 \%$ are depending on mineral water as bottled water. No one uses water from ponds or from the rain. As far as the accessibility for different sources of water are concerned majority of the sampled households are accessing their water from personal water sources as around $68 \%, 27.1 \%$ are accessing the water from personal and shared sources, $9.7 \%$ are accessing from public water sources, while the remaining $0.7 \%$ are using bottled water. The household water usage pattern reveals that, $72.3 \%$ of households are using same water for all their purposes, $16 \%$ of households are different only for drinking, $9.3 \%$ of them are consuming water differently for drinking and cooking, while the remaining percentage of 2.3 defers in drinking, cooking and bathing. 56.78\% of households are consuming well water for their drinking purposes, while $36.9 \%$ of households are using boiled and cooled water, and $11.6 \%$ are depending on filtered water, while the fourth category depends on bottled water. It is to be noted that in the sample no household uses rain water for drinking purposes. Where water is free from pollution it is considered low risk. The consumer is safe. Each household has a different opinion about safety. Most of them said 
boiled water was safer than any other category, while $16 \%$ of them agreed filtered water was safe, and around $8 \%$ of the households say that rain water is safe. Further after explanation of the gravity of the situation, $91.33 \%$ of households revealed their preference to switching to rain water harvesting, as the alternative source for drinking purposes. For not switching they gave lack of space or money non availability or both as reasons.

\section{Discussion based on the regression analysis}

Before ascertaining the client willingness to pay, the attempt was made to assess the willingness to join (WTJ). This analysis was carried out by using the probit (Green, 2012) model. In totality the model was significant at $1 \%$ level. In this model the dependent variable was WTJ. The manifestation of willingness was assigned one and unwillingness zero. At the end of probit analysis the researchers found that the variable media exposure index (Mei) and the household size (Hhz) influenced the household WTJ positively at $1 \%$ significant level.

Table 1. Household WTJ for RWHS Probit regression output

\begin{tabular}{ll}
\hline Explanatory variable & \multicolumn{1}{c}{$\begin{array}{c}\text { Dependent variable: } \\
\text { WTJ for RWH }\end{array}$} \\
\hline Age (years) & 0.009 \\
& $(0.0107)$ \\
Edu (years) & $0.021^{* *}$ \\
& $(0.039)$ \\
Hhz (number) & $0.039 * * *$ \\
& $(0.1029)$ \\
Dgen (Dummy) & 0.179 \\
& $(0.3879)$ \\
Inc (rupees) & $4.52 *$ \\
& $(6.14)$ \\
Docp (Dummy) & 0.202 \\
& $(0.388)$ \\
Mei (Index) & $0.239 * * *$ \\
& $(0.6222)$ \\
Ext (sq. Meters) & $0.163 *$ \\
& $(0.0969)$ \\
Intercept & 0.105 \\
& $(0.9675)$ \\
No of observation & 285 \\
LR chi2 (32) & 6.61 \\
Prob $>$ chi2 & 0.0009 \\
Log likelihood & -90.4357 \\
Pseudo R & 0.0853 \\
Note: $* * *$ statistically significant at $1 \%, * *$ statistically significant at $5 \%, *$ statistically significant at $10 \%$, figures in \\
the parenthesis are standard error. & \\
&
\end{tabular}

From this it can be inferred that the use of available media of all kind and types, to the maximum, to explain the level of effects of water pollution and the consequent health hazards generated in the peninsula, create awareness of the impending danger to residents clearly. This results in the decision of these people in seeking a sustainable and durable solution to the emergency thus driving them towards RWHS. Besides these two factors the 
household education, income and the extent of land are found to be statistically significant and manifested a positive sign on the WTJ of the householders. It is possible however that a higher household income would result in a trend towards the RWHS. The corollary is that even when the householder income does not permit they too can be included in to the program by extending a credit facility. The RWHS can also be granted on repayments in installments to those who cannot afford the project. The various non-government agencies could be accessed to deliver these facilities on a grant basis. Those who are successfully educated and realize the criticality of the situation would come forward. Their WTJ would be positive.

Table 2. Household WTP for RWHS: Multinomial Logit regression out-put

\begin{tabular}{|c|c|c|c|c|}
\hline \multirow[t]{2}{*}{ Explanatory variable } & \multicolumn{4}{|c|}{$\begin{array}{c}\text { Dependent variable: willingness to pay for rain water } \\
\text { harvesting(WTP) }\end{array}$} \\
\hline & Small & Medium & Large & Extra large \\
\hline Age & $\begin{array}{l}0.023 \\
(0.021)\end{array}$ & $\begin{array}{l}0.0256^{*} \\
(0.0235)\end{array}$ & $\begin{array}{l}0.03 \\
(0.028)\end{array}$ & $\begin{array}{l}0.022 \\
(0.0266)\end{array}$ \\
\hline Edu & $\begin{array}{l}0.017 * * \\
(0.07947)\end{array}$ & $\begin{array}{l}0.17 * \\
(0.0902)\end{array}$ & $\begin{array}{l}0.133^{* *} \\
(0.107)\end{array}$ & $\begin{array}{l}0.001 * * \\
(0.0981)\end{array}$ \\
\hline Hhz & $\begin{array}{l}0.034 \\
(0.1977)\end{array}$ & $\begin{array}{l}0.213 \\
(0.221)\end{array}$ & $\begin{array}{l}0.246^{*} \\
(0.274)\end{array}$ & $\begin{array}{l}0.285 \\
(0.2566)\end{array}$ \\
\hline Dgen & $\begin{array}{l}0.061 \\
(0.72)\end{array}$ & $\begin{array}{l}(0.54) \\
(0.9003)\end{array}$ & $\begin{array}{l}0.925 \\
(1.245)\end{array}$ & $\begin{array}{l}19.327 * * * \\
(2.468)\end{array}$ \\
\hline Inc & $\begin{array}{l}9.39 * * \\
(0.00001)\end{array}$ & $\begin{array}{l}0.00001^{* *} \\
(0.000)\end{array}$ & $\begin{array}{l}-6.87 \\
(0.000)\end{array}$ & $\begin{array}{l}0.00002 \\
(0.00001)\end{array}$ \\
\hline Docp & $\begin{array}{l}0.577 \\
(0.795)\end{array}$ & $\begin{array}{l}0.274 \\
(0.967)\end{array}$ & $\begin{array}{l}0.565 \\
(1.301)\end{array}$ & $\begin{array}{l}1.266 \\
(0.895)\end{array}$ \\
\hline Mei & $\begin{array}{l}0.684 * * \\
(1.240)\end{array}$ & $\begin{array}{l}0.449^{*} \\
(1.446)\end{array}$ & $\begin{array}{l}2.233^{*} \\
(1.618)\end{array}$ & $\begin{array}{l}0.567 * \\
(1.683)\end{array}$ \\
\hline Ext & $\begin{array}{l}0.189 \\
(0.173)\end{array}$ & $\begin{array}{l}0.115 \\
(0.191)\end{array}$ & $\begin{array}{l}0.045^{*} \\
(0.254)\end{array}$ & $\begin{array}{l}0.381 * \\
(0.1976)\end{array}$ \\
\hline Intercept(constant) & $\begin{array}{l}0.031 \\
(1.895)\end{array}$ & $\begin{array}{l}4.307^{*} \\
(2.252) \\
\end{array}$ & $\begin{array}{l}3.173 \\
(2.642) \\
\end{array}$ & 22.726 \\
\hline No of obs & 285 & & & \\
\hline LR chi2(32) & 0.1768 & & & \\
\hline Prob $>$ chi 2 & 0.0072 & & & \\
\hline Log likelihood & -367.8498 & & & \\
\hline Pseudo $\mathrm{R}^{2}$ & 0.1768 & & & \\
\hline
\end{tabular}

Descriptive statistic showed that about $89 \%$ of the respondents are willing to pay (WTP) for rainwater harvesting if it should rain as clean water for drinking. About $11 \%$ were not interested in rain water harvesting with some giving reasons as they have adequate water from underground water source, and do not have enough space for installing harvesting system, and do not have economic facility to maintain high investment on installment costs and have to face difficulties due to dirty roofs because of excessive dust in the areas and asbestos roofs. 
Multinomial logistic regression is used to model nominal outcome variables, in which the log odds of the outcomes are modeled as a linear combination of the predictor variables. The households those who are not willing to pay for a RWHS was chosen as base category. The chi- square value of 44.29 is highly significant $(\mathrm{p}>0.0072)$ at $1 \%$ significant level this indicates that the explanatory variables included in the model jointly influence the households' WTP for alternative water source as RWHS. The parameter estimate of multinomial logit only provides direction and not probability or magnitude of change. From the results, the WTP for small, medium, large and extra-large RWHS relative to households who are not willing to pay for RWHS is significantly determined by education of respondent, income of household, media exposure index, household size, extent of house occupied land, age and sex of respondent. The formulated multinomial logistic model was able to identify certain socioeconomic variables associated with the WTP for rainwater harvesting. Diagnostic test were conducted on the model to ascertain the authenticity and predictive justification of the model. This model presents the $\log$ likelihood value of 367.85 The Likelihood Ratio Index or Pseudo $\mathrm{R}^{2}$ is test the goodness of the model. A pseudo $\mathrm{R}^{2}$ value of 0.1768 shows how the model explains $17.6 \%$ of variations in the dependent variable. By this way the model fits the set of observations. This show how the WTP variable is influenced by set of independents variables (Arlinghaus and Mehner, 2004)

Table 3. Relative risk ratio out-put Multinomial logistic regression

\begin{tabular}{|c|c|c|c|c|}
\hline \multirow[t]{2}{*}{ Explanatoryvariable } & \multicolumn{4}{|c|}{$\begin{array}{c}\text { Dependent variable: willingness to pay for rain } \\
\text { water harvesting(WTP) }\end{array}$} \\
\hline & Small & Medium & large & Extra-large \\
\hline Age & $\begin{array}{l}1.023 \\
(0.0215)\end{array}$ & $\begin{array}{l}1.026 \\
(0.0241)\end{array}$ & $\begin{array}{l}1.03 \\
(0.029)\end{array}$ & $\begin{array}{l}1.022 \\
(0.027)\end{array}$ \\
\hline Edu & $\begin{array}{l}1.017 \\
(0.081)\end{array}$ & $\begin{array}{l}1.186 \\
(0.107)\end{array}$ & $\begin{array}{l}1.142 \\
(0.123)\end{array}$ & $0.999(0.098)$ \\
\hline Hhz & $\begin{array}{l}0.966 \\
(0.191)\end{array}$ & $\begin{array}{l}1.238 \\
(0.274)\end{array}$ & $\begin{array}{l}1.27 \\
(0.351)\end{array}$ & $1.329(0.341)$ \\
\hline Dgen & $\begin{array}{l}1.063 \\
(0.765)\end{array}$ & $\begin{array}{l}1.717 \\
(1.546)\end{array}$ & $\begin{array}{l}2.522 \\
(3.14)\end{array}$ & $2.480(6.11)$ \\
\hline Inc & $\begin{array}{l}1.00 \\
(0.00001)\end{array}$ & $\begin{array}{l}1.00 \\
(0.0000)\end{array}$ & $\begin{array}{l}1.000 \\
(0.0000)\end{array}$ & $\begin{array}{l}1.000(0.0000 \\
1)\end{array}$ \\
\hline Docp & $\begin{array}{l}1.78 \\
(1.415)\end{array}$ & $\begin{array}{l}0.76 \\
(0.735)\end{array}$ & $\begin{array}{l}0.568 \\
(0.739)\end{array}$ & $\begin{array}{l}3.547 \\
(3.173)\end{array}$ \\
\hline Mei & $\begin{array}{l}0.504 \\
(0.626)\end{array}$ & $\begin{array}{l}1.567 \\
(2.265)\end{array}$ & $\begin{array}{l}0.107 \\
(0.173)\end{array}$ & $\begin{array}{l}0.567 \\
(0.955)\end{array}$ \\
\hline Ext & $\begin{array}{l}1.208 \\
(0.209)\end{array}$ & $\begin{array}{l}1.121 \\
(0.215) \\
\end{array}$ & $\begin{array}{l}0.956 \\
(0.243) \\
\end{array}$ & $\begin{array}{l}1.464 \\
(0.289) \\
\end{array}$ \\
\hline No of obs & 285 & & & \\
\hline LR chi2(32) & 44.29 & & & \\
\hline Prob $>$ chi 2 & 0.0072 & & & \\
\hline Log likelihood & -367.849 & & & \\
\hline Pseudo $\mathrm{R}^{2}$ & 0.1768 & & & \\
\hline
\end{tabular}

The results from the multinomial logistic model results are shown in above tables. The dependent variable has five categories, which are not switching to rainwater harvesting, 
small harvesting system, medium harvesting system, large and extra-large harvesting system. The not switching to rain harvesting system is taken as base category. In the sample taken for consideration it was seen that years of education range from 3 to 26 with the mean education of 13.41 years with a standard deviation of 3.26 years. According to the analyzed data from the multinomial logistic model, the education was positively correlated with willingness to pay for rainwater harvesting system. The research outcome indicated 5\% significant level of education for the small, large and extra-large Rain water harvesting system, on the other hand $10 \%$ of significant level for medium system of rain water harvesting. When the data of this research was analyzed it revealed that education had a positive effect in the desire to adopt rain water harvesting system. It was observed that the higher the educational standards the greater was the appreciation and understanding towards the adoption of rain water harvesting system. Nevertheless, the educated population do not tend to appreciate the value of rain water harvesting system due to their ability to spend money on purchasing of mineral water. Paradoxically however people at large with moderate education have a tendency to take advice seriously and consider more diligently of the advantage of rain water harvesting.

Even though the educated category understand the effects of water pollution and importance of rain water conservation, they do not seem to have a tendency to pay for these systems. Since these systems are acceptable to the large majority of the people whose economy is restricted, it would be feasible to make them invest in these systems. If a credit facility could be afforded with the package of reasonable latent time period for repay, it would be possible to adopt the rain water harvesting system throughout the peninsula. The opinion of the researchers is that if the Eranaimadu diversion scheme funds are used to supply the rain water harvesting systems, the peninsula can be made successful in the endeavor of supplying drinking water while maintaining the sustainability of the project throughout the peninsula.

The media exposure index (MEI) was obtained by observing how many accessed with what regularity the media supplying relevant information. Where they accessed the media frequently the points awarded was six and where there was no access what so ever the points allocated were zero. Thus it was possible to identify those who would accommodate rainwater harvesting system and those who would not at all. This variable was introduced in the assumption that people with substantial knowledge in exposure to relevant mass media coverage in water pollution, water conservation and water security they would have a positive attitude towards adoption of rain water harvesting. According to the research carried out by Abdul Sattar and Eatzaz Ahmed (2009) to find out the willingness to pay for quality drinking water of Hydra pad city, the media index was selected as independent variable. In the researcher point of view, MEI was positively correlated with the WTP for Rain water harvesting for the adoption of small, medium, extra-large and large system. This has 5\% significant level in extra-large, on the other hand large and medium has $10 \%$ significant on extra rain water harvesting system. As researcher hypothesis it was seen that more the knowledge and understanding of prevailing fresh water conditions of peninsula greater was the motivation to secure RWH system at house hold level. It has been also found that among those who have an understanding of the status of water pollution prefer to obtain the larger RHW system available. This expression of the degree of confidence they have in the system. Further knowledge of the changing climate also could lead them to the above preference in consideration of reduced rainfall. The other reason for this preference could be the economic advantage against bottle water and environmental concern.

Within the research area it was seen that the highest income was Rs. 168000 per mensem with the minimum income being Rs. 10000 per mensem the standard deviation being Rs. 25680/- and the mean being Rs.43000/-. The multinomial logit analysis exhibited a positive 
correlation with the selection of rainwater harvesting system. The research sees relationships between the income and desire to obtain rain water harvesting system. The desire to obtain rain water harvesting system is proportional to the increasing income standards. Creating credit facilities for low income groups will motivate them go for rain water harvesting system.

The real estate extent is positively correlated with rainwater harvesting system of extra large at $10 \%$ of significant level. The factor that motivates this preference is seen as the possession of large stretches of land. When land is available the rainwater harvesting system can be installed without much loss of space proportionately. In the central municipal council area the house occupied land area which is very small due to the infrastructure of the town. But in the peripheral region, the respondent has large extent of land. Where the land is large the change of mind set is towards the installment of rain water harvesting system. Occupation of the respondent has no relation with the selection of harvesting system in term of extra-large. The researcher expected that those employed in health related occupation are more likely to express their WTP than those employed with non-health related occupation. This is because of their mentality and experience better off relative to the other occupations. Yet since the variable, 'occupation' how it influences the trend of thought cannot be determine by the authors because the variable is statistically insignificant. Age of the respondent appears to be positive with medium rain water harvesting system, which is in $10 \%$ of significant level. Age does not have the expected negative sign. This suggests that older persons are more willing to pay for rainwater harvesting. This was evidenced since most respondents reason out that it is worthwhile contributing for the future of their children. They have the confidence that most of the underground water will go under pollution continuously by various ways. So they do not like to depend solely on ground water as drinking source. The household size was found to be significant and positively correlated as far as the large sized RWHS are concerned. This may be due to the fact that the family was large and accordingly the need for larger amounts of water. Finally gender is highly significant in the system of extra-large. That expresses a positive correlation. This variable indicated the fact that most of the respondents interviewed were males and men are the economically empowered in the cultural setting of Jaffna peninsula. This may be the possible reason the positive correlation between gender and the preference.

\section{CONCLUSIONS}

The results of this study reveals that majority of the households in the Jaffna peninsula are willing to invest in RWHS, supporting the idea of substituting considerable amount of available ground water supply with rain water throughout the region. The media exposure index influenced the household WTJ positively at $1 \%$ significant level, implying the ability to successfully use available media to provide information about water pollution and consequent health hazards generated in the peninsula. The age, education, household income and the extent of real estate are found to be statistically significant and manifested a positive sign on the WTJ. It was observed that the majority with high educational standards tend to appreciate the adoption of RWHS. Nevertheless highly educated households do not seem to appreciate the RWHS probably due to their financial strength to purchase mineral water.

Households with moderate education showed a tendency to accept advise yet consider the offensive effects as against the advantage of RWHS. It is evident that creating credit facilities for low income groups to motivate the households to go for RWHS. If a credit 
facility could be afforded with the package of reasonable latent time for repay it would be possible to adopt the RWHS throughout the Jaffna peninsula.

\section{REFERENCES}

Sattar. A. and Ahmed. E. (2009).Willingness to pay for quality of drinking water. Department of Economics Quaid-I-Azam University, Islamabad.

Annette Prüss-Ustün et al., (2014). Burden of disease from inadequate water, sanitation and hygiene in low- and middle-income settings: a retrospective analysis of data from 145 countries, Trop. Med. Int. Health., 19, No.8, 894 - 905.

Balendran, V.S. et al., (1968). Groundwater resources of Jaffna Peninsula. Water Resource Board, Colombo.

Bateman, Ian J. and Turner, R. Kerry. (1995). "Valuation of the Environment,Methods and Techniques: The Contingent Valuation Method", in Turner (ed).Sustainable Environmental Economics and Management: Principles and Practice England: J Wiley.

Damador N. Gujarati (2003). Basic Economertics, $4^{\text {th }}$ ed. McGraw Hill

Green, W.H. (2012). Econometric Analysis. $7^{\text {th }}$ ed.Upper Saddle River, NJ: Prentice Hall.

Hosmer, D.W, et al., (2013). Appiled Logistic Regression. $3^{\text {rd }}$. Hoboken. NJ: Wily.

Ifabiyi, I.P. (2011) Willingness to Pay for Water at Household Level in Ilorin, Kwara State, Nigeria. Global Journal of Human Social Science, Volume 11 Issue 2 Version 1.0 March 2011 Double Blind Peer Reviewed International Research Journal., Global Journals Inc. (USA).

Long, J.S.(1997). Regression Model of Catercorical and Limitted Dependent Variables. Thousand Oaks, CA: Sage.

Long, J.S and J. Frees (2006). Regression Model of Catercorical Dependent Variables Using Stata. $2^{\text {nd }}$ ed. College.

Moffat, B. et al., (2009). Households Willingness to pay for Improved Water Quality and Reliability of Supply InChobe Ward, Maun.

Nandakumar,V. (1983). Natural Environment and groundwater contamination in the Jaffna peninsula.University of Tsukuba, Ibaraki, 305, 155 - 164.

Quartey, J.D. (2011). Towards a Sustainable Allocation of Potable Water in Ghana: Evidence from Kumasi Ministry of water Resources, Works and Housing, Ghana Water Journal Forum I ${ }^{\text {st }}$ Edition, Pg 194.

Rajasooriyar, L.D, et al., (2002). Groundwater quality in the Valigamam region of the Jaffna Peninsula, Sri Lanka. In: Sustainable groundwater management. Hiscock, K.M., Rivett, M.O., Davison, R.M. (Eds). Geological Society, London. 193, 181 - 197. 
Treiman, D.J. (2009). Qantitative Data anlysis: Doing Social Research toTest Ideas. San Fancisco; Jossey Bass.

WHO, and UNICEF (2014). Joint Monitoring Program (JMP) for water supply and sanitation 